11.

Filosofía del derecho 



\title{
RAWLS E O DIREITO. A ORDEM JURÌDICA NA TEORIA DA JUSTIÇA COMO EQUIDADE
}

[Rawls and Law. The Legal System in the Theory of Justice as Fairness]

\author{
Marcos Rohling* \\ Instituto Federal de Educação, Ciência e Tecnologia Catarinense, \\ Câmpus Videira, Brasil
}

\begin{abstract}
RESUMEN
Asumiendo que las cuestiones que rodean el debate sobre la teoría de la justicia de Rawls no tienen por objeto discutir el problema del sistema jurídico, principalmente porque el autor no se ha dedicado a abordar tal cuestión, se busca, en este trabajo, discutir el concepto y los calificadores del sistema jurídico. El texto se divide en cuatro partes: la primera está destinada a la problematización del derecho y de las instituciones legales como parte de las instituciones de la estructura básica de la justicia como equidad; la se-
\end{abstract}

\begin{abstract}
Assuming that the issues regarding the debate on Rawls' theory of justice are not aimed at discussing the problem of the legal system, mainly because the author has not approached such matter, this work discusses the concept and the qualifiers of the legal system. The text is divided in four sections: the first section is about the problematization of law and legal entities as part of the institutions of the basic structure of justice as fairness The second section is about realising what an institution is, of
\end{abstract}

RECIBIDO el 8 de marzo y ACEPTADO el 30 de mayo de 2015

* Professor do Instituto Federal de Educação, Ciência e Tecnologia Catarinense, Câmpus Videira. Doutorando em educação na Universidade Federal de Santa Catarina; mestre em filosofia y graduado em filosofia pela Universidade Federal de Santa Catarina, graduando em direito pela Universidade do Sul de Santa Catarina. Endereço, Instituto Federal Catarinense, Câmpus Videira, Rodovia SC 135, Campo Experimental, CEP, 89560-000, Videira, SC, Brasil. Correio eletrônico, marcos_roh@ yahoo.com.br 
gunda de ellas tiene la intención de darse cuenta de lo que es una institución, de su constitución por reglas y normas de carácter público, destinadas a personas racionales y de la propia concepción de reglas; en la tercera parte se pretende acercar el sistema legal y sus componentes a la tensión entre la justicia formal y justicia substancial; por último, en la cuarta parte, se discuten los principios que componen el ideal del Estado de derecho, que es la transformación de la aplicación de la justicia formal al sistema jurídico, teniendo en cuenta apuntar a la perspectiva de que los derechos individuales, especialmente la prioridad de la libertad, son objeto principal de su protección.

\section{Palabras Clave}

Sistema jurídico - Estado de derecho - Justicia formal - Instituciones jurídicas - Rawls. how its constitution is based on public rules and regulations made for rational people and regarding the very conception of the rules. The third section is about considering the legal system and its components to handle the tension between the formal justice and the substantial justice. Finally, the fourth section discusses the principles that make up the ideal of rule of law, which changes how formal justice applies to the legal system, which considers that individual rights, especially the priority of liberty, are its main object of protection.

\section{KEYWORDS}

Legal System - Rule of Law - Formal Justice - Judicial Institutions - Rawls.

\section{INTRODUÇÃO**}

Nos estudos a respeito da teoria política de Rawls, há certa percepção de que o autor não oferece um tratamento adequado e sistemático a respeito do direito. Em trabalhos, como os de Viola ${ }^{1}$ e Richardson \& Weithman ${ }^{2}$, essa ausência fica evidente: enquanto nos textos colecionados por Richardson $\&$ Weithman a respeito da obra de Rawls não há nenhum dedicado

** No presente texto, usar-se-ão as seguintes abreviações: DwORKIn, R., A justiça de toga = Dworkin, Ronald, $A$ justiça de toga (São Paulo, Martins Fontes, 2010); Dworkin, R., Levando os direitos a sério $=$ DwOrkIN, Ronald, Levando os direitos a sério (2a edição, São Paulo, Martins Fontes, 2007); RaWls, J., Teoria = RaWLS, John, Uma teoria da justiça (São Paulo, Martins Fontes, 2009); Vıola, F., Rawls e il diritto = VIOLA, Francesco, Rawls e il diritto, em Biblioteca della libertà (2013), XLVIII, pp. 163-173; Voice, P., Rawls Exp. = Voice, Paul. Rawls Explained (Chicago, Open Court, 2011); Volpato Dutra, D. J., Just. proc.. = Volpato Dutra, Delamar J., Justiça processual e substantiva na filosofia prática contemporânea, em BAVARESO, Agemir - Hobuss, João (organizadores), Filosofia, justiça e direito (Pelotas, EDUCAT, 2005).

${ }^{1}$ Viola, F., Rawls e il diritto, pp. 163-173.

${ }^{2}$ Richardson, Henry - Weithman, Paul (organizadores), Philosophy of Rawls. A Collection of Essays (New York, Garland, 1999). 
ao direito, Viola claramente indica que não há, por parte de Rawls e dos estudos nele inspirados, uma particular atenção demandada ao direito, o qual é assumido como um modelo procedimental de regulação social, apoiado nos princípios da igualdade e da reciprocidade. ${ }^{3}$ De fato, são poucos os trabalhos publicados sobre o tema na obra de Rawls. Recentemente, em Rawls and Law (2012), Brooks publicou uma coletânea de artigos dedicados ao tema do direito e de áreas afins no pensamento de Rawls, tais quais o constitucionalismo, a teoria democrática, o igualitarismo, o feminismo, a justiça global, o liberalismo político, o estado de direito e a razão pública, especialmente nas disciplinas de direitos constitucional, internacional e privado, entre outros. Além disso, é também verdade que, em 2003, foi organizado um Simpósio sobre a influência de Rawls sobre o direito, oportunidade na qual se abordou diferentes matizes da obra do filósofo em sua relação com a ordem jurídica. ${ }^{4}$ No entanto, ainda assim a ponderação realizada, num e noutro sentido, naquilo que Viola argumenta, é uma influência de Rawls sobre o direito estabelecido e constituído. ${ }^{5}$

$\mathrm{O}$ direito, como uma instituição presente no interior da teoria de Rawls, tal como aparece nos trabalhos de Dworkin ${ }^{6}$, Lois ${ }^{7}$, Sarlo $^{8}$, Viola ${ }^{9}$, Rohling e Volpato Dutra ${ }^{10}$, é claramente um dos aspectos menos explorados da teoria política do autor. É bem verdade que, por uma questão de rigor, há uma explicação aceitável para isso, vale dizer, a de que a teoria da justiça de Rawls é uma teoria da justiça distributiva, de cariz social. No entanto, se esse é o caso, também é verdade que é uma teoria da justiça social distributiva, no âmbito da qual a ordem jurídica é abordada como uma instituição pertencente à estrutura básica da sociedade. Há, assim, uma discussão do direito mediante a qual se estabelece uma relação deste com a teoria política, de forma a se poder corretamente dizer haver uma

${ }^{3}$ VIOLA, F., Rawls e il diritto, pp. 163.

${ }^{4} \mathrm{O}$ simpósio em questão, Symposium, Rawls and the Law, foi organizado na Fordham Law e publicado na Fordham Law Review, 72 (2004), p. 1381-2285 [disponível em, http, //ir.lawnet.fordham.edu/fr/vol72/iss5/; acessado em 23/04/2010].

${ }^{5}$ ViOLA, F., Rawls e il diritto, pp. 163-4.

${ }^{6}$ Dworkin, R., A justiça de toga, pp. 241-62.

${ }^{7}$ LoIs, Cecília Caballero, O direito e o sistema dos direitos em John Rawls. Fundamento, validade e abrangência de uma teoria universal, em BUENO, Roberto (organizador), Racionalidade, justiça e direito. Ensaios em filosofia do direito (Uberlândia, EDUFU, 2013), pp. 303-319.

${ }^{8}$ Sarlo, Oscar, Supuestos de teoría jurídica en John Rawls, em Revista de Ciencias Sociales (Universidad de Valparaíso), 47 (2002), p. 319-322.

${ }^{9}$ Viola, Francesco, Rawls e il diritto, pp. 163-173.

${ }^{10}$ Rohling, Marcos - Volpato Dutra, Delamar José, $O$ direito em "Uma teoria da justiça” de Rawls, em Dissertatio, 34 (Universidade de Pelotas, 2011) 2, pp. 63-89. 
justificação política para a existência da ordem jurídica, dada nos termos da prioridade da liberdade.

Partindo-se da teoria política de Rawls, o ordenamento jurídico em questão é caracterizado como sendo um sistema jurídico de uma democracia constitucional, isto é, de uma sociedade que Rawls especifica como sendo bem ordenada e, portanto, regulada por uma concepção pública de justiça. Assim, incorpora-se à estrutura jurídica, fundada numa democracia constitucional, a ideia de que ela é composta por uma constituição, a qual é encarregada do estabelecimento da igual cidadania; assegurando, pois, a liberdade da pessoa, a liberdade de pensamento e de consciência, assim como a igualdade política, traduzida em termos de sufrágio universal e o direito de participar do processo político. Assim sendo, o sistema jurídico, organizado de um modo tal que mantenha a ordem pública, é derivado da função que tem o Estado de zelar pela equidade através da mantença das condiçôes indispensáveis para que os indivíduos possam perseguir seus interesses e cumprir com suas obrigaçóes, tais como as entendam por si mesmos. ${ }^{11} \mathrm{~A}$ hipótese desse texto é a de que a ordem jurídica emanada dos preceitos de justiça, muito embora seja descrita por Rawls como aquela que seria seguida por qualquer sistema de normas que incorporasse com perfeição a ideia de um sistema legal, inclusive positivista, estabelece conexōes com padrões mais elevados de moralidade, os princípios de justiça, o que, então, conduz à defesa de uma perspectiva que restabeleça as relaçôes entre direito e moral.

O presente texto será, então, tendo em vista dar conta do objetivo indicado, arquitetado de modo a traduzir-se em quatro momentos distintos: em primeiro lugar, problematizar-se-á o tema do direito e da ordem jurídica como parte das instituições da estrutura básica da justiça como equidade; em segundo lugar, por sua vez, pretende-se dar conta do que é uma instituição, da sua constituição por regras e normas de caráter público, destinadas a pessoas racionais (noção que está no âmago da definição de sistema jurídico), e da própria concepção de regras; em terceiro lugar, dando sequência, desenvolve-se uma abordagem do sistema jurídico e dos seus elementos constituintes, notadamente, a tensão entre justiça formal e justiça substantiva, no âmbito do qual emerge o ideal de estado de direito ("Rule of Law"); por fim, em quarto lugar, discutem-se os princípios que compõem o ideal de estado de direito("Rule of Law"), que é a transformação da aplicação da justiça formal ao sistema jurídico, tendo em vista

${ }^{11}$ Navarro, Emílio Martínez, Solidaridad liberal. La proposta de John Rawls (Granada, Comares, 1999), p. 230. 
apontar para perspectiva de que os direitos individuais, especialmente a prioridade da liberdade, são o objeto primário de sua proteção.

\section{O DIREITO E A ORDEM JURÍDICA NA “JuSTICE AS FAIRNESS": O DIREITO COMO INSTITUIÇÃO}

Como afirmado anteriormente, Rawls não tem por objetivo desenvolver uma teoria do direito, mas fala da ordem legal à medida que esclarece o problema da liberdade igual, dentro da estrutura básica da sociedade, a qual, por meio de suas principais instituiçôes, é o objeto de aplicação dos princípios de justiça. Voice indica duas razões relacionadas, pelas quais essas instituições são importantes: em primeiro lugar, elas têm uma função normativa de atribuição de direitos e deveres, isto é, estabelecer um quadro de 'deveres' que (idealmente) governam as interações entre os cidadãos. Como exemplo, tome-se a instituição que atribui o direito de propriedade aos cidadãos na propriedade em si e no lucro que é derivado de seu uso (embora ambos os direitos sejam limitados em muitos aspectos, em estados liberais democráticos reais). Aos cidadãos, portanto, deveria ser permitida a posse dos meios de produção, sendo que os outros cidadãos têm o dever de respeitar esse direito, em que a posse apropriada dos meios de produção é compatível com os princípios da justiça ${ }^{12}$.

Em segundo lugar, essas instituições são mantidas pela ameaça de coerção. O Estado usa o seu monopólio do poder coercitivo para fazer cumprir os requisitos normativos da instituição. Todavia, claramente, uma instituição como a propriedade privada dos meios de produção é muito importante quando se considera o modo com os quais os benefícios e encargos da cooperação social são distribuídos. O sistema jurídico é outra instituição que Rawls menciona ao descrever a estrutura básica da sociedade. Por exemplo, é óbvio que a maneira pela qual um sistema legal define uma pessoa com personalidade jurídica seja fundamental para a forma como os cidadãos fazem reivindicações uns sobre os outros. $\mathrm{O}$ que faz com que essas instituiçôes políticas, econômicas e sociais básicas tenham um efeito profundo sobre a vida dos cidadãos. Essas instituições encaixam-se num sistema que governa as interações do dia a dia entre os cidadãos da forma mais fundamental. É por isso que Rawls chama de uma estrutura básica, que fornece o quadro no qual os cidadãos interagem com o Estado e entre $\mathrm{si}^{13}$.

Embora a estrutura básica da sociedade, como indica Mandle, abranja

\footnotetext{
${ }^{12}$ Voice, P., Rawls Expl., p. 33.

${ }^{13}$ Voice P., Rawls Expl., p. 34.
} 
mais do que a ordem jurídica e política, é inegável que tais instituições ocupam um papel especial, posto controlarem o modo como os outros elementos, que formam tal estrutura, relacionam-se entre si. Assim, embora não seja verdadeiro que uma sociedade seja coletivamente responsável apenas por suas leis, não se pode negar que é por meio delas que uma sociedade toma decisóes explícitas, coletivas e vinculativas ${ }^{14}$. Sendo assim, se, por um lado, nesse contexto teórico, Rawls não teve por objetivo desenvolver uma teoria sobre o direito, mas o conceitua em sua relação com a proteção das liberdades individuais, nos termos da aplicação da justiça formal fazendo emergir o estado de direito ou o império do direito ("Rule of Law"), por outro lado, não se pode negar que, de suas ideias sobre as instituições de uma sociedade bem ordenada e, portanto, de uma sociedade justa, é possível caracterizar o que vem a ser um sistema jurídico justo ${ }^{15}$.

Com efeito, para Rawls, os princípios da justiça têm duas funções específicas, a saber: primeiramente, os princípios da justiça encarnam ideais abstratos que proporcionam a base para a unidade social numa sociedade bem ordenada; em segundo lugar, os princípios têm a função de permitir a avaliação da justiça de políticas e fornecer orientações práticas para a formulação leis ${ }^{16}$. Notadamente, para Rawls, os princípios da justiça são inicialmente aplicados à estrutura básica da sociedade que é composta pela constituição, a economia, o sistema social, como a família, assim como a distribuição de bens e recursos.

Nessa senda, o direito, cuja função o vincula à proteção da liberdade,

${ }^{14}$ Mandle, John, Rawls's A Theory of Justice. An Introduction (Cambridge University Press, New York, 2009), pp. 78-79.

${ }^{15}$ Uma vez que seja assim, sem problematizar a questão maior dentro da qual está envolvida a discussão sobre o direito, vai-se caracterizar neste tópico somente o sistema jurídico pensado por Rawls para uma sociedade justa.

${ }^{16}$ Freeman, Samuel, Rawls (New York, Taylor \& Francis, 2007), p. 199. Conforme se deu a entender anteriormente, numa sociedade liberal, na qual inexiste uma doutrina filosófica, moral ou religiosa predominante e vinculada e defendida pelo Estado -inclusive, um dos pilares do liberalismo, isto é, a laicidade do Estado-, Freeman argumenta que uma concepção compartilhada de justiça é necessária para unificar as pessoas de tal sorte a serem capazes de conviver harmoniosamente na mesma sociedade. Nos trabalhos posteriores, esse aspecto ficará mais evidente, sobretudo, por enfatizar que os princípios da justiça social têm a função de promover a unidade social, servindo, pois, como uma espécie de carta pública para sociedade bem ordenada, proporcionando, desse modo, uma base de justificação pública entre as pessoas com diferentes pontos de vista, sejam eles, religiosos, morais e filosóficos. O papel público de uma concepção de justiça é vinculado a um conceito redefinido por Rawls, a saber, a razão pública, que aparece rapidamente em Teoria com outro sentido. Essa abordagem da razão pública caracteriza o entendimento de Rawls de uma democracia constitucional. 
é visto como uma das principais instituições - permeando, inclusive, as demais instituiçôes elementares- que formam a estrutura básica da sociedade, devendo ele, assim como as demais instituiçóes, ser regulado pelos princípios da justiça. Há, nesse aspecto, o encontro da justiça substantiva, definida pelos princípios da justiça, que assumem o papel da justiça, com a justiça formal, que encerra o princípio da legalidade, estabelecendo, por conseguinte, um sistema jurídico justo, cuja função precípua é a de estabelecer uma base para expectativas legítimas ${ }^{17}$, no sistema de cooperação social, que é a sociedade bem ordenada. Um sistema jurídico, assim caracterizado, é uma ordem coercitiva de normas públicas com a finalidade de regular a conduta de pessoas racionais, ao mesmo tempo em que fomenta a estrutura da cooperação social, de modo a assegurar aos indivíduos, pela via da coerção, a proteção das liberdades fundamentais, fortalecendo o compromisso, mediante a estrutura da cooperação social, com a obediência ao direito. Nos tópicos subsequentes, serão analisados os conceitos correlacionados ao sistema jurídico.

\section{O DIREITO COMO INSTITUIÇÃO PÚBLICA REGULADA POR REGRAS}

Para que se compreenda o que é o direito, visto sob a via da instituição, é preciso dizer o que, para Rawls, é uma instituição e como se estabelece a sua relação com a justiça formal. De modo simples, essas ideias inicialmente foram desenvolvidas por Rawls no $\$ 10$, de Teoria, e são cruciais pois que as regras que se aplicam às instituiçôes básicas da sociedade são igualmente aplicadas ao direito, enquanto sistema público de regras. Para isso, é primordial acentuar que os princípios de justiça, que orientam a atribuição de direitos e deveres, bem como determinam a distribuição dos benefícios e encargos da vida social, são primariamente destinados à estrutura básica da sociedade, tendo em conta sua organização em um esquema de cooperação ${ }^{18}$. Os qualificadores de uma instituição, nesse contexto, valem também para o sistema jurídico. Nesse sentido, Rawls afirma que:

${ }^{17} \mathrm{O}$ conceito de expectativas legítimas é fundamental na compreensão da temática do direito e da sua observância em Rawls, ainda que não se restrinja a ele. De forma simples, as expectativas legítimas surgem quando as pessoas cumprem com as suas obrigaçôes, quando participam ou estão engajadas em algum empreendimento mutuamente cooperativo, como é o caso do direito. Ao cumprirem as suas parcelas de responsabilidades, por assim dizer, elas dão mote à origem de expectativas legítimas. Isto é, são expectativas e requerimentos institucionais em face do cumprimento da parcela corresponde a cada qual, não guardando, por isso, conexão com algum correlato moral.

${ }^{18}$ Rawls, J., Teoria, p. 66. 
"por instituição, entendo um sistema público de normas que define cargos e funçôes com seus direitos e deveres, poderes e imunidades etc. Essas normas especificam que certas formas de ação são permissíveis e outras, proibidas; e estipulam certas penalidades e defesas, e assim por diante, quando ocorrem transgressōes. Como exemplos de instituições ou, de forma mais geral, de práticas sociais, podemos citar jogos e ritos, julgamentos e parlamentos, mercados e sistemas de propriedade" 19 .

Daí se depreende um elemento crucial quanto à concepção de regras, pois elas estabelecem ações como permitidas, para as quais são criados mecanismos para assegurar sua efetividade, assim como especificam proibiçōes decorrendo delas certas penalizaçōes. É notório que essa descrição de Rawls é demasiadamente geral, abarcando, por conseguinte, não só o ordenamento jurídico, mas práticas sociais como um todo. Numa sociedade bem ordenada, o papel dos princípios de justiça, assumindo o papel que cabe à justiça, é o de especificar e avaliar o sistema de regras que constituem as instituições básicas da sociedade, tendo em conta que todas essas instituiçõos são necessárias para a cooperação social. As regras, então, devem satisfazer à concepção de justiça. Com efeito, nenhuma sociedade pode existir sem regras determinadas, pois elas permitem o desenvolvimento das principais atividades de uma sociedade uma vez que "[...] fazem a produção econômica, o comércio e o consumo possível. Nem poderia suportar por muito tempo uma sociedade sem algum mecanismo político para a resolução de disputas e decisões, revisão, interpretação e execução das suas consequências econômicas e outras normas de cooperação, ou sem alguma forma de a família, para reproduzir, sustentar e nutrir os membros das suas gerações futuras. É isso que distingue as instituições sociais que constituem a estrutura básica de outras instituiçōes sociais profundamente influentes, tais como a religião, e outras instituições sociais não são básicas porque não são geralmente necessárias para a sociedade e para a cooperação social (mesmo se elas podem ser ideologicamente necessárias manter as sociedades em particular e para manter seu status quo)"20.

Não obstante, ao afirmar que uma instituição -a estrutura básica da sociedade, por consequência-é um sistema público de regras, Rawls está a dizer que todos os que estão nela engajados sabem o que saberiam se essas regras e a sua participação na atividade que elas definem fosse o resultado de um acordo. Isso sugere que se uma pessoa faz parte de uma instituição, então, ela deve saber o que as regras exigem dela e dos outros, assim como,

${ }^{19}$ Ibíd.

${ }^{20}$ Freeman, Samuel. Original Position, em The Stanford Encyclopedia of Philosophy (2012) [disponivel em: http, //plato.stanford.edu/archives/spr2012/entries/ original-position/; cessado em 21/10/14]. 
igualmente, deve saber que os outros sabem disso e que eles sabem que disso ela também sabe. O que há, no fundo, é a questão da publicidade das regras institucionais, pois se supõe que há um entendimento sobre o que especificam e o que proíbem, em termos de espaço público, sob pena de não existir uma base segura para as expectativas legítimas. Assim, "A divulgação das normas da instituição garante que aqueles nela envolvidos podem saber que limitaçóes de conduta esperar uns dos outros e quais são os tipos de atividade permissíveis. Há um fundamento comum para a definição das expectativas mútuas. Ademais, em uma sociedade bemordenada, que é regulada de forma eficaz por uma concepção compartilhada de justiça, também há um entendimento público no tocante ao que é justo e ao que é injusto" 21 .

As regras, conforme Rawls as trata, têm a seguinte distinção. Elas podem ser: $i$ ) regras constitutivas de uma instituição tendo em vista que estabelecem seus vários direitos e deveres, entre outros; e ii) estratégias e regras de conduta, que são relativas ao modo de como se tirar o melhor proveito da instituição para propósitos particulares. Conforme argumenta Rawls, as estratégias e regras de condutas racionais, que em si mesmas não são partes de uma instituição, baseiam-se numa análise de quais ações permissíveis os indivíduos e os grupos vão escolher em vista de seus interesses, crenças e conjecturas que fazem sobre os planos uns dos outros e, ainda que sejam importantes para a avaliação das instituições e práticas sociais relevantes, não são pertencentes aos sistemas públicos de regras institucionais que as definem. As regras constitutivas, por sua vez, são vistas como pertencentes a uma instituição. Nesse sentido, a teoria de uma instituição toma as regras constitutivas como dadas e analisa o modo pelo qual o poder é distribuído, explicando como aqueles engajados nela provavelmente irão se valer de suas oportunidades. Ainda assim,

Ao elaborar e reformar organizações sociais, é preciso, naturalmente, examinar os sistemas e as táticas que permite e as formas de comportamento que tende a incentivar. O ideal é que se definam as regras de tal maneira que as pessoas sejam levadas por seus interesses predominantes a agir de modos que promovam fins sociais desejáveis. A conduta dos indivíduos norteada por seus planos racionais deve ser coordenada, tanto quanto possível, para atingir resultados que, embora não pretendidos ou nem previstos por eles, sejam, não obstante, os melhores do ponto de vista da justiça social ${ }^{22}$.

Éà luz dessa conjuntura teórica, que Rawls define institucionalmente o

\footnotetext{
${ }^{21}$ RaWls, J., Teoria, pp. 67-8.

${ }^{22}$ Ibíd., p. 68.
} 
direito, ou seja, como um conjunto de normas públicas. Segundo sustenta, "o sistema legal é uma ordem coercitiva de normas públicas voltada para pessoas racionais, com o propósito de reger sua conduta e prover a estrutura da cooperação social"23. Quando essas regras são justas, afirma o autor, elas estabelecem uma base para expectativas legítimas e constituem as bases que possibilitam que as pessoas confiem umas nas outras e reclamem, com razão, quando tais expectativas são frustradas. Num sistema de cooperação social, lembrando o "fair play", é pertinente e, até certo ponto, necessário que cada uma das partes cumpra a sua parte no esquema geral, o que, de fato, permite que se estabeleça uma base segura para a confiança mútua e para as expectativas legítimas. Desse modo, portanto, pode-se concluir que: "Se as bases dessas reivindicaçôes forem incertas, incertos também serão os limites das liberdades dos indivíduos. [...].Pressupondo-se que essas normas são equitativas ou justas, basta que os indivíduos se filiem a essas organizações e aceitem os benefícios daí resultantes para que as obrigações decorrentes constituam as bases de expectativas legítimas" ${ }^{24}$.

Seguramente, nesse contexto, quando essas regras são justas, elas estabelecem uma base para expectativas legitimas. Ao contrário, se as bases dessas reivindicações forem incertas, ou duvidosas, os limites das liberdades individuais também o serão. Esse aspecto reflete o fundo liberal do pensamento de Rawls, sentido no qual o indivíduo é livre para fazer o que a lei permite: a lei é o espaço da liberdade porque ela é dada pela liberdade.

Rawls aduz que naturalmente outras regras compartilham as características acima indicadas. É assim que as regras de jogos e de associaçóes privadas, entre outras, destinam-se a pessoas racionais tendo em vista modelar suas atividades. Ora, uma vez que essas regras, pressupostamente, sejam justas e equitativas, então, conclui o autor, basta que um grupo de indivíduos filie-se a essas organizaçôes e aceite os benefícios daí resultantes, para que as obrigaçôes decorrentes constituam as bases para expectativas legítimas. Contudo o que distingue um sistema jurídico de outros conjuntos de normas públicas endereçadas a pessoas racionais é sua extensão e abrangência e seus poderes regulares em relação às associações da sociedade. Nesse sentido, Rawls aduz que os "[...] organismos constitucionais definidos por esse sistema geralmente têm o direito legal exclusivo de exercer pelo menos as formas mais extremas de coerção. Os tipos de coerção que as associações privadas podem empregar são rigorosamente limitados. Ademais, a ordem legal exerce uma autoridade última sobre um determinado território bem definido. Ela é também marcada pela extensa gama de atividades que rege

\footnotetext{
${ }^{23}$ Ibíd., p. 291.

${ }^{24}$ Ibíd.
} 
e pela natureza fundamental dos interesses que se destina a assegurar. Essas características simplesmente expressam o fato de que a lei define a estrutura básica no âmbito da qual se dá o exercício de todas as outras atividades" ${ }^{25}$.

O sistema jurídico tem, desse modo, institucionalmente, o monopólio do direito legal de exercer as formas mais extremas da coação, circunscrita a um determinado território. Essa definição, como indicado anteriormente, enfileira-se no lastro de alguns teóricos, entre os quais, de Weber, que definia o direito como o monopólio da coação e da violência, dentro de um determinado território ${ }^{26}$. Além disso, como visto, a ordem jurídica caracteriza-se pela extensa gama de atividades que regula e pela natureza fundamental dos interesses que se destina a assegurar. Noutros termos, a ordem jurídica tem o poder de normatizar as demais instituições sociais haja vista a extensão de atividades que regula, as quais são conjugadas aos interesses por ela assegurados.

Além disso, vale dizer que é notável o modo como Rawls administra, no âmbito do sistema jurídico, a relação entre direito e moral. Como arguido, Rawls, e outros pensadores contemporâneos, como Dworkin e Habermas, reinserem certos aspectos de moralidade no direito. No caso de Rawls, isso significa dizer que o direito deve ser norteado pelos princípios de justiça, os quais, mediante a administração regular da justiça, fazem surgir o estado de direito, cuja função precípua é a proteção das liberdades básicas. Nessa via, no lastreio de Fuller, o direito rawlsiano é caracterizado por algo similar a moralidade interna, sob a via dos princípios de justiça. Conforme sustenta Rawls, esses são efetivamente a base de uma moralidade política, e que podem perfeitamente bem serem extensíveis à esfera do direito ${ }^{27}$.

Sem embargo, no lastro de Kelsen e Hart, o direito constitui-se ainda, para Rawls, num sistema público de regras, o qual determina e regula seu próprio funcionamento, que deve ser pautado, em última instância, pela justiça e pela eficiência. É notório que, embora guiado por princípios de justiça, que são morais, estabelecendo, por conseguinte, a sua validade, o direito é uma esfera que é guiada por regras de sua própria estrutura, ainda que norteado por princípios de justiça. Ao ser considerado que uma lei injusta permanece, apesar de sua injustiça, uma lei válida, compreende-se melhor que o direito é responsável por reconhecer, mediante critérios, certos requisitos que conferem validade. Assim, o direito estabelece seus

${ }^{25}$ Ibíd., 291-292.

${ }^{26}$ Weber, Max, Economia e sociedade. Fundamentos da sociologia compreensiva (Brasília, DF, Universidade de Brasília, 1999), II, pp. 526.

${ }^{27}$ RaWLs, J., Teoria, p. 272. Isso quer dizer que os princípios de justiça, que são o núcleo da moralidade política, também são o núcleo da esfera do direito, como instituição. 
próprios requisitos formais de validade que, em determinadas circunstâncias, podem admitir a existência de ordenações legais injustas.

\section{A JUSTIÇA FORMAL (JUSTIÇA COMO REGULARIDADE) E A JUSTIÇA SUBSTANTIVA}

Rawls assinala a distinção entre o que chama de justiça substantiva e justiça formal ${ }^{28}$, sendo a última à adesão a princípios, ou como alguns têm dito, entre os quais, Perelman, a observância ao sistema. Quanto à justiça formal, Volpato Dutra afirma que "Na formulação de Rawls, quando uma certa concepção de justiça assume o papel da justiça, definindo direitos e deveres fundamentais, determinando a distribuição de recursos e oportunidades e é aplicada imparcial e consistentemente, tem-se, então, a justiça formal. A justiça formal, assim, independe de princípios substantivos. Ela é aplicada igualmente, mesmo que seus princípios substantivos possam ser injustos, como em um sistema discriminatório. Essa igualdade está implicada na própria noção de direito. Cabe observar que mesmo essa justiça exclui formas significantes de injustiça, pois, através da imparcialidade exigida, ela assegura a segurança. Mesmo com leis injustas é melhor que elas sejam consistentemente aplicadas, pois é melhor do que a arbitrariedade" 29 .

Rawls sugere a utilização da terminologia justiça como regularidade em vez da de justiça formal. Trata-se, pois, de uma identificação evidente com a finalidade desta tendo em vista que justiça como regularidade traduz melhor a ideia de que é uma administração imparcial, guiada por outra coisa senão por regras. Regularidade, portanto, traduz mais adequadamente essa ideia. Entretanto, nesse contexto, o sistema jurídico institucionalmente é um sistema público de regras destinado às pessoas racionais para sua orientação, estabelecendo, por conseguinte, bases seguras para as expectativas legítimas. A lei, como uma de suas regras, é concebida, pois, como uma diretriz endereçada a pessoas racionais estabelecendo e precisando a liberdade para agir. Institucionalmente, suas regras devem satisfazer os princípios de justiça, que assumiram o papel da justiça, como uma con-

${ }^{28}$ Fuller desenvolveu uma perspectiva congruente entre justiça substantiva e justiça formal. Quanto a isso, Volpato Dutra, D. J., Just. proc., pp. 135-136, assevera que, para esse autor, "a justiça substantiva e a formal caminhavam juntas, pois regras injustas dificilmente seriam aplicadas imparcial e consistentemente, pois a vagueza das leis deixaria espaço para a arbitrariedade no caso particular. Portanto, onde o Estado de Direito é respeitado e há segurança jurídica, igualmente se encontra justiça substantiva, ou seja, reconhecimento de direitos e liberdade dos outros e distribuição equitativa de bens".

${ }^{29}$ Volpato Dutra, D. J., Just. proc., pp. 135. 
cepção de justiça, de tal forma que fornecem uma atribuição de direitos e deveres fundamentais, bem como determinam a divisão das vantagens advindas da cooperação social.

Com efeito, esse modo de entender exige que os juízes e demais autoridades tenham uma administração imparcial e consistente das instituições e das leis, independentemente de quais sejam seus princípios fundamentais - ou seja, casos similares são tratados de modo similar, sendo as similaridades e as diferenças identificadas pelas normas existentes. A regra, correta definida pelas instituições, é regularmente observada e adequadamente interpretada pelas autoridades - é a justiça formal, que, aplicada ao sistema jurídico, faz surgir o estado de direito (o império do direito "Rule of Law"). Uma vez que a ideia de igualdade é latente à concepção de justiça formal, bem como está implícita na própria noção de lei e de instituição, depreende-se a exigência de que, em sua administração, as leis e as instituiçôes se devem aplicar igualmente àqueles que pertençam às categorias definidas por elas. Assim, a justiça formal é a obediência ao sistema jurídico-político no qual se vive; na esteira de Perelman, é, portanto, a adesão ao princípio.

Conforme Rawls salienta, obviamente que o fato de as leis e as instituiçôes serem igualmente executadas, que tratar casos semelhantes de modo similar, não é garantia de não se incorrer em injustiças, pois isso não basta para assegurar a justiça substantiva. A justiça substantiva, conforme o autor entende, depende dos princípios de acordo com os quais a estrutura básica de uma sociedade é montada. Assim, a justiça substantiva depende dos princípios de justiça, definidos, no caso de Rawls, na posição original.

A despeito desse aspecto, qual seja, aquele da relação entre a justiça substantiva e a justiça formal, principalmente no que tange à injustiça de leis e instituiçôes, tendo em vista o impedimento de arbitrariedades, Rawls recebeu forte influência de Fuller, pois, ao afirmar que alguns dizem que: "[...] a justiça formal e a justiça substantiva de fato costumam caminhar juntas e que, por conseguinte, pelo menos as instituiçóes flagrantemente injustas não são nunca, ou pelo quase nunca, administradas de maneira imparcial e coerente" ${ }^{30}$, o filósofo político está justamente remetendose à afirmação deste autor de que há conexão entre as justiças formal e substantiva, pois onde quer que se encontre a justiça formal, o estado de direito e o respeito às expectativas legítimas, encontra-se, igualmente, a justiça substantiva. De fato, Fuller desenvolveu uma perspectiva congruente entre justiça substantiva e justiça formal. ${ }^{31}$ Quanto a isso, Volpato Dutra

\footnotetext{
${ }^{30}$ Rawls, J., Teoria, pp. 72.

${ }^{31}$ Fuller, Lon L., The Morality of Law (Revised Edition, Chicago, Chicago Uni-
} 
assevera que, para esse autor "[...] a justiça substantiva e a formal caminhavam juntas, pois regras injustas dificilmente seriam aplicadas imparcial e consistentemente, pois a vagueza das leis deixaria espaço para a arbitrariedade no caso particular. Portanto, onde o Estado de Direito é respeitado e há segurança jurídica, igualmente se encontra justiça substantiva, ou seja, reconhecimento de direitos e liberdade dos outros e distribuição equitativa de bens ${ }^{32}$.

Embora inicialmente Rawls fosse reticente em relação à afirmação do entrelaçamento da justiça substantiva com a justiça formal, isso se dava porque àquela altura não havia ainda a determinação dos princípios razoáveis da justiça substantiva, bem como as condições em que os homens os escolhem e vivem de acordo com eles. Uma vez que, na posição original, escolhem-se esses princípios, é, por conseguinte, possível estabelecer os vínculos entre a justiça substantiva e a justiça formal, conquanto que se endosse a concepção de justiça que estabelecem. Certo é que o conteúdo dos princípios da justiça determina a justiça substantiva. E, assim, a justiça formal atua na administração imparcial do que preceituam estes princípios. É assim que quando a justiça formal é aplicada ao sistema jurídico, surge o estado de direito. ${ }^{33}$

\section{O Estado de Direito ou o império da lei ("Rule of LaW”)}

Ao considerar que o estado de direito ("Rule of Law") é a transformação da aplicação da justiça formal, que é equitativa, ao sistema jurídico, Rawls tem em vista apontar para a perspectiva de que os direitos individuais, especialmente a prioridade da liberdade, são objeto primário de sua proteção. Notoriamente, esse conceito de estado de direito, forjado nas fileiras do kantismo, permite, pois, estabelecer a forma do direito que, grosso modo, é correspondente, preservadas as devidas particularidades, ao conceito de legalidade weberiano, isto é, ao monopólio legítimo da coação ${ }^{34}$. De tal forma, como característica fundamental do estado de direito, a legalidade é o que determina, na teoria de Rawls, a forma do direito. Portanto, a forma kantiana do direito, em Rawls, é dada pelo conceito de estado de direito. Desse modo, é permitido dizer que, na teoria rawlsiana, os preceitos do estado de direito são, inequivocamente, qualificações do sistema jurídico, através do qual se divisa a forma do direito. Evidentemente, para Rawls, existe uma íntima relação entre o estado de direito e a liberdade expressada,

\footnotetext{
versity Press, 1969), pp. 184-186.

${ }^{32}$ Volpato Dutra, Delamar José, Just. proc., pp. 135-6.

${ }^{33}$ Rawls, J., Teoria, pp. 290-291.

${ }^{34}$ Volpato Dutra, Delamar José, Just. Proc., pp. 135.
} 
sobretudo, quando se considera o sistema jurídico e a profunda conexão com os preceitos que definem a justiça formal.

Uma vez que se entenda que, na concepção de Rawls, o sistema jurídico é um sistema de normas públicas dirigidas a pessoas racionais, podem-se explicitar os princípios da justiça associados aos preceitos que definem o estado de direito os quais são "os que seriam seguidos por qualquer sistema de normas que expressasse com perfeição a ideia de um sistema legal" ${ }^{35}$. Certamente, e esse é um aspecto relevante a ser considerado, não se espera e nem se pretende dizer que as leis concretas necessariamente satisfazem esses preceitos em todos os casos, pois aqui se encontra não mais na teoria ideal, mas na teoria não ideal, na qual a sociedade concreta encontra imperfeiçôes. Trata-se, pois, de uma sociedade quase justa, que difere daquela sociedade bem ordenada, da teoria ideal, em que não ocorrem violações severas dos princípios da justiça e todos cumprem com a sua fração na cooperação social. Nesse sentido, porque esses preceitos derivam de uma noção ideal, espera-se que as leis aproximem-se dele, senão em todos os casos, mas, na maioria das vezes.

Inversamente, se os desvios em relação à justiça formal -entenda-se a justiça como regularidade- forem muito difundidos, é permissível, afirma Rawls, questionar e indagar se, de fato, o que se tem é um sistema jurídico e não apenas uma coleção de ordens particulares da qual o interesse é a proteção e a promoção dos interesses de um ditador ou o ideal de um déspota benevolente. Essa é uma questão séria uma vez que tem claro que o presente estado de direito, alinhado a um sistema jurídico, é destinado a uma sociedade democrática, constitucionalmente amparada. ${ }^{36}$ Embora Rawls argumente que, para essa questão, não existe uma resposta clara, ele, contudo, afirma que a razão de se pensar numa ordem jurídica como sistema de normas públicas está no fato de que essa condição permite deduzir os preceitos associados com o estado de direito, que numa sociedade democrático-constitucional, é também denominado de princípio da legalidade.

\footnotetext{
${ }^{35}$ Rawls, J., Teoria, p. 292.
}

${ }^{36}$ Nesse ponto, vale dizer que, a partir do que preceitua Rawls, pode haver Estado em que a liberdade não é preservada, isto é, Estado sem direito. Diametralmente oposto, quando um Estado age no sentido da proteção das liberdades iguais fundamentais, especificadas, sobretudo pelo primeiro princípio, esse Estado passa a ser um estado de direito, e ainda, democrático, pois se destina a uma democracia constitucional. É interessante contrastar uma tal posição como aquela de Kelsen, para o qual todo Estado é um estado de direito. Sobre esse tema, recomenda-se: Volpato Dutra, Delamar J., A legalidade como forma do estado de direito, em Kriterion, 109 (2004) 1, pp. 57-80. 
Ora, pode-se dizer que, em circunstâncias iguais, uma ordem jurídica é administrada justamente, mais que qualquer outra, se ela satisfizer mais perfeitamente os preceitos do estado de direito, isto é, ela será tanto mais justa quanto mais de acordo com a legalidade ela estiver. Assim sendo, Rawls afirma que o estado de direito fornecerá “[...] uma base mais sólida para a liberdade e um meio mais efetivo de organizar sistemas de cooperação. Todavia, pelo fato de garantirem apenas a administração imparcial e regular das leis, sejam quais forem, esses preceitos são compatíveis com a injustiça. Eles só impõem exigências um tanto fracas à estrutura básica, mas limites que não são de modo algum desprezíveis" ${ }^{37}$.

Dimana, então, que o estado de direito, embora vagamente, limita a estrutura básica da sociedade de tal forma a dirimir a injustiça e a aplicação desigual da lei, bem como de estatutos jurídicos, de um modo geral, diante dos direitos individuais, que é o objeto primário da sua proteção ${ }^{38}$.

No trato dado a esta temática, assegurando a proteção dos direitos individuais no seio de uma sociedade democrática, Rawls postula os seguintes preceitos como pertencendo ao estado de direito, mais amiúde: i) o preceito dever implica poder; ii) o preceito casos semelhantes devem receber tratamentos semelhantes; iii) o preceito de que não há ofensa sem lei; e iv) os princípios da justiça natural. Esses preceitos são válidos como regras e princípios para o sistema jurídico, que, de certo modo, regula as demais instituições da estrutura básica da sociedade. Por conseguinte, são diretrizes que garantem a legalidade da ordem jurídica.

No que se refere ao primeiro preceito elencado, qual seja, o princípio segundo o qual dever implica poder, Rawls argumenta que ele faz emergir algumas características elementares do sistema jurídico, a saber: $i$ ) de acordo com a primeira delas, as açóes exigidas ou proibidas pelo estado de direito devem ser do tipo que seja razoável supor que os homens podem fazer ou evitar. Assim deve ser porque um sistema de regras destinadas a pessoas racionais para organizar sua conduta deve estar preocupado com o que essas pessoas podem ou não fazer. De fato, Rawls argumenta que um sistema jurídico "não deve impor um dever de fazer o que não é possível fazer" ${ }^{39}$; ii) a segunda característica, evidenciada na ideia de que o dever implica poder, transmite a noção de que aqueles que estabelecem as leis e dão ordens, fazem-no de boa fé. Segundo Rawls, leis e ordens são aceitas como tal apenas se existe a crença de que podem ser obedecidas e executadas, pois, "[...] Se houver dúvidas quanto a isso, é de presumir que os

\footnotetext{
${ }^{37}$ Rawls, J., Teoria, pp. 292-3.

${ }^{38}$ Ibíd., pp. 292-293.

${ }^{39}$ Ibíd., p. 293.
} 
atos das autoridades têm algum outro objetivo que não o de organizar a conduta dos cidadãos" ${ }^{20}$; iii) a terceira característica, por fim, expressa a exigência de que um sistema jurídico deve reconhecer a impossibilidade de execução e obediência como uma defesa, ou pelo menos, caso não o possa, que seja considerado como um atenuante. A razão para tal, argumenta o autor, é a de que, ao impor regras, “o sistema jurídico não pode considerar irrelevante a incapacidade de cumprimento" ${ }^{41}$ posto que seria, contrariamente, "um fardo insuportável para a liberdade se a possibilidade de sofrer sanções não se limitasse normalmente a atos de que temos a capacidade de participar ou não"42.

O estado de direito é, ainda, envolvido pelo preceito da isonomia, ou seja, o de que casos semelhantes devem receber tratamento semelhante. Para Rawls, a importância desse preceito está no fato de que, sem ele, as pessoas não poderiam regular suas ações por meio de regras, porquanto, embora Rawls admita que as próprias regras jurídicas forneçam os critérios de semelhança, assim como os princípios para interpretá-las, esse preceito limita significativamente a discrição dos juízes, no caso desses se encontrarem diante de alguma lacuna do direito, como Dworkin denomina, que exija seu poder discricionário, e de outros que ocupam cargos de autoridade. Assim posto, esse preceito força a autoridade legal "a justificar as distinções que estabelecem entre pessoas por referência aos princípios e às normas jurídicas pertinentes" ${ }^{43}$. Sob esse aspecto, esse preceito do sistema jurídico coloca em relevo a coerência, pois, ilustrando a influência de Anatomy of the Law, de Fuller, Rawls aduz que "Em qualquer caso específico, se as leis forem algo complicadas e exigirem interpretação, pode ser fácil justificar uma decisão arbitrária. Mas, à medida que aumenta o número de casos, torna-se mais difícil elaborar justificativas plausíveis para julgamentos tendenciosos. A exigência de coerência vale naturalmente para a interpretação de todas as leis e para justificativas em todos os níveis. Por fim, acaba ficando difícil formular os argumentos fundamentados para juízos discriminatórios, e a tentativa de fazê-lo torna-se menos convincente. Esse preceito vale também em casos de equidade, isto é, quando se deve abrir uma exceção porque a norma vigente provoca um dano inesperado. Mas com a seguinte ressalva: uma vez que não há uma linha divisória clara que separe esses casos excepcionais, chega-se a um ponto, como nas questões de interpretação, em que quase todas as diferenças terão importância. Nesses

\footnotetext{
${ }^{40}$ Ibíd.

${ }^{41}$ Ibíd..

${ }^{42}$ Ibíd.

${ }^{43}$ Ibíd., p. 294.
} 
casos, aplica-se o princípio da autoridade, e basta o peso da jurisprudência ou do veredicto anunciado" ${ }^{44}$.

Dworkin mesmo, em sua própria teoria do direito, considera a coerência com suma importância, pois dela depende a integridade do direito. Isto é, diante de casos em que as regras jurídicas são insuficientes por não haver uma resposta no ordenamento jurídico através das leis, casos em que o juiz deve usar seu poder discricionário, ele deve fazê-lo tendo em conta a coerência com os princípios tomados por fundamento, mantendo a integridade do ordenamento jurídico. Assim, segundo Dworkin, "coerência aqui significa, por certo, coerência na aplicação do princípio que se tomou por base, e não apenas na aplicação da regras específica anunciada em nome desse princípio" ${ }^{45}$.

Ademais, num artigo que produziu no qual vê e interpreta Rawls como um jurista ${ }^{46}$, Dworkin afirma que as ideias do autor direcionam-se, quanto a isso, no mesmo sentido em que sua tese, pois “[...] considera que as pessoas têm o direito não apenas àquilo que as instituições legislativas determinam especificamente, mas também à elaboração baseada em princípios de tais determinações. A coerência é a melhor proteção contra a discriminação./ [...] Observa-se a ênfase de Rawls na complexidade como uma limitação em si mesma, e sua insistência em que a coerência se aplica [...] a 'todas as normas [...] em todos os níveis" "47.

A essa altura, a conclusão de Dworkin é a de que os cidadãos ficam mais bem protegidos contra a arbitrariedade ${ }^{48}$ e a discriminação quando os juízes que interpretam o e elaboram o direito nos casos difíceis, nas lacunas do direito, são responsáveis pela coerência, não meramente com doutrinas específicas, mas, com a coerência baseada em princípios que abrangem toda a estrutura do direito. ${ }^{49}$ É bem verdade que Dworkin, ao criticar o poder discricionário do juiz, defendido larga e abertamente pelos positivistas, entre os quais Hart, persiste na distinção entre regras, princípios e políticas e sustenta que, quando inexistirem regras claras disponíveis, são

${ }^{44}$ Ibíd.

${ }^{45}$ DwOrkin, R., Levando os direitos a sério, pp. 139.

${ }^{46}$ Tal artigo foi revisto e publicado no livro Justiça de Toga, por Dworkin. Sobre essa interpretação, recomenda-se, RoHLIng, Marcos, Dworkin e a interpretação de Rawls como filósofo do direito, em Lex Humana, 4 (2012), pp. 102-124.

${ }^{47}$ Dworkin, R., A Justiça de Toga, pp. 353-354.

${ }^{48}$ Para Perelman, Chaïm, Ética e direito (São Paulo, Martins Fontes, 1996), pp. 216, no que diz respeito à discricionariedade judicial, "uma distinção será considerada arbitrária quando não se puder indicar motivo evidente ou funcional, conforme à natureza das coisas, razoável, relevante e, pelo menos, não desarrazoado, que permita justificá-la”.

${ }^{49}$ Dworkin, R., A Justiça de Toga, p. 354. 
os princípios que, com base na integridade e na coerência, devem inspirar e orientar os juízes, principalmente no respeita aos casos difíceis ${ }^{50}$.

O estado de direito, assim como o sistema jurídico, é determinado ainda pelo preceito da legalidade, expresso na noção de que não há ofensa sem lei ("nullum crimen sine lege"). Segundo Rawls, do ordenamento jurídico, espera-se as seguintes ações: $i$ ) que as leis sejam conhecidas e expressamente promulgadas; ii) que seu significado seja claramente definido; iii) que os estatutos sejam genéricos, tanto na forma, quanto na intenção, e que não sejam usados como um meio de prejudicar determinados indivíduos que possam ser expressamente nomeados (decretos confiscatórios); iv) que as infrações mais graves sejam interpretadas estritamente; e $v$ ) que as leis penais não sejam retroativas em detrimento daqueles aos quais se aplicam.

Naturalmente, e Rawls afirma isso, essas exigências do preceito de que não há ofensa sem lei estão todas implícitas na noção de regulamentação do comportamento por normas públicas, uma vez que "[...] se, por exemplo, as leis não forem claras naquilo que permitem e proíbem, o cidadão não saberá como se comportar. Além disso, embora possa haver ocasionais decretos confiscatórios ou leis retroativas, essas coisas não podem constituir características comuns ou típicas do sistema. Caso contrário, conclui-se que ele tem outra finalidade. Um tirano pode alterar sem aviso prévio, e consequentemente punir (se é que essa é a palavra correta) seus súditos, porque sente prazer em ver quanto tempo eles levam para descobrir, mediante a observação das penalidades que lhes são infligidas, quais são as novas leis. Essas normas, porém, não constituiriam um sistema legal, pois não serviriam para organizar o comportamento social oferecendo uma base para expectativas legítimas" ${ }^{51}$.

Torna-se claro que, através do preceito da legalidade, o estado de direito, como elemento distintivo do sistema jurídico, deve prover e promover, através da regulação social, uma base sólida e segura para as expectativas legítimas, aquelas que são calcadas na cooperação social, que derivam de uma concepção de justiça distributiva, quando cada qual, cada membro de uma sociedade democrática cumpre com a sua parte no quinhão social ${ }^{52}$.

Por fim, Rawls argumenta que o estado de direito é, ainda, determinado pelos preceitos que definem a justiça natural, os quais devem, dentro do ordenamento jurídico, assegurar que a ordem jurídica seja imparcial e regularmente mantida. Segundo Rawls, esses preceitos são concebidos

${ }^{50}$ DwOrkin, R., Levando os direitos a sério, pp. 23-72, especialmente, pp. 35-46.

${ }^{51}$ RaWls, J., Teoria, p. 295.

${ }^{52}$ É evidente que, para Rawls, exista uma ligação entre as expectativas legítimas e a legislação penal. No entanto, dados os limites dessa investigação, não se explanará acerca desse tema. 
para preservar a integridade do processo jurídico, aspecto no qual o filósofo segue a análise de $\mathrm{Hart}^{53}$. Agindo segundo esses preceitos que definem a justiça natural, Rawls argumenta no sentido de assegurar a proteção da liberdade ao estabelecer que os órgãos penais, dentro do sistema jurídico, devem respeitar o devido processo legal para a imputação de penas, certamente depois de respeitadas todas as normas para averiguação da culpa e do cometimento de uma infração ou qualquer ato delituoso. Uma vez que Rawls afirma, valendo-se de Hart, que essa ideia decorre de um senso de justiça natural tradicional, pode-se remeter aos princípios processuais presentes na cultura jurídica anglofônica para estabelecer as bases desses preceitos da justiça natural.

De fato, Hart afirma que os preceitos da justiça natural, no âmbito do direito, são também conhecidos como os princípios processuais, e que aqueles como "audi alteram partem" ou "ninguém pode ser juiz em causa própria” são concebidos como exigências da justiça. Assim é porque eles afiançam imparcialidade ou objetividade, tendo em vista que são arquitetados para assegurar que o direito seja aplicado a todos aqueles -e só aqueles- que são semelhantes no aspecto relevante fixado pelo próprio direito ${ }^{54}$.

Ademais, Rawls entende que "Se as leis são diretrizes com o intuito de orientar pessoas racionais, os tribunais devem preocupar-se com a aplicação e o cumprimento dessas leis de maneira apropriada" 55 , posto que, desse modo, estariam agindo de maneira a proteger e garantir os direitos fundamentais dos membros dessa sociedade. É, pois, com base nesses preceitos da justiça natural que se entende que "Deve haver um esforço escrupuloso para decidir se houve infração e impor a penalidade correta" ${ }^{56}$, haja vista que seria um fardo insuportável para a liberdade o sofrimento de sanções de modo arbitrário e sem a lisura de um processo íntegro, imparcial e justo. ${ }^{57}$ Em resumo, Rawls está a falar de exigências mínimas estabelecidas pelos preceitos da justiça natural, validando todo o procedimento para que o processo possa ser legítimo, imparcial e de acordo com a justiça.

Desse modo, Rawls faz as seguintes distinções, uma vez que um sistema jurídico deve: $i$ ) estabelecer disposições para a condução ordenada de julgamentos e audiências; ii) conter normas quanto às provas, garantindo procedimentos racionais de informação; iii) exigir, por meio do estado de direito, embora haja variações quanto a esses procedimentos, alguma forma

\footnotetext{
${ }^{53}$ Rawls, J., Teoria, pp. 295-296.

${ }^{54}$ Hart, H. L. A., O conceito de direito (3a edição, Lisboa, Fundação Calouste Gulbenkian, 2001), pp. 175.

${ }^{55}$ Rawls, J., Teoria, pp. 295.

${ }^{56}$ Ibíd., pp. 295.

${ }^{57}$ Ibíd., pp. 291.
} 
de processo devido, isto é: um processo razoavelmente concebido para verificar a verdade, de modo coerente com os outros objetivos do sistema jurídico, para se saber se ocorreu uma violação e em quais circunstâncias ela foi realizada. Como ilustração, Rawls dá o seguinte exemplo: “[...] os juízes devem ser independentes e imparciais e ninguém pode julgar em causa própria. Os julgamentos devem ser justos e abertos, mas não ser influenciados pelo clamor popular. Os preceitos da justiça natural objetivam assegurar que a ordem legal será mantida de forma regular e imparcial" 58 .

Do exemplo dos juízes, podem-se abstrair algumas preciosas implicaçōes para o sistema jurídico. Entre elas, pode-se afirmar que os juízes devem ser independentes e imparciais, jamais podendo, como se observa, julgar em causa própria, no sentido que Hart aduz, acima exposto. Além disso, os julgamentos devem ser justos e abertos, mas não podendo ser influenciados pelo clamor público.

Definitivamente, esses preceitos que definem o estado de direito na teoria política de Rawls estão claramente em íntima conexão com a liberdade. Uma vez que se entenda que a liberdade é um complexo de direitos e deveres definidos pelas instituições, "As diversas liberdades especificam coisas que podemos optar por fazer, se assim o desejarmos, e nas quais, quando a natureza da liberdade as torna apropriadas, todos têm um dever de não interferir" "59. Esse aspecto é semelhante àquela caracterização da liberdade desenvolvida por Montesquieu segundo a qual é permissível fazer tudo o que, dentro dos limites da lei, sob a égide da não intervenção alheia e estatal, ela permitir que seja feito:

Num Estado, isto é, numa sociedade em que há leis, a liberdade não pode consistir senão em poder fazer o que se deve querer e em não ser constrangido a fazer o que não se deve desejar: "[...] A liberdade é o direito de fazer tudo o que as leis permitem; se um cidadão pudesse fazer tudo o que elas proíbem, não teria mais liberdade, porque os outros também teriam tal poder" ${ }^{\prime \prime} 0$.

É nesse sentido que se entende a afirmação categórica de Rawls de que, uma vez que não seja respeitado o preceito do estado de direito de que não há ofensa sem lei através da imprecisão e vagueza das leis, o que se tem a liberdade de fazer, ou não, fica igualmente vago e impreciso. Dito de outro modo, se uma lei for imprecisa e incerta, esclarece Rawls, a liberdade para agir dentro da estrutura básica da sociedade também será imprecisa e incerta, fincando limitado o exercício da liberdade por um temos razoável,

\footnotetext{
${ }^{58}$ Ibíd., pp. 296.

${ }^{59}$ Ibíd., pp. 262.

${ }^{60}$ Montesquieu, O espirito das leis (São Paulo, Abril Cultural, 1985), p. 148.
} 
e, consequentemente, não haverá meios que possibilitem a criação de uma base para expectativas legítimas ${ }^{61}$.

Obviamente, a relação com a liberdade dá-se também com os outros preceitos do estado de direito $^{62}$. Rawls indica que o mesmo tipo de consequência ocorre quando os demais preceitos do estado de direito não são respeitados, de forma que o exercício da liberdade fica comprometido e limitado. Assim "Resultam-nos mesmos tipos de consequência os casos semelhantes que não são tratados de maneira semelhante, se falta ao processo judicial a integridade essencial, se a lei não reconhece a impossibilidade de cumprir o dever legal como uma defesa, e assim por diante. $\mathrm{O}$ princípio da legalidade encontra, então, um fundamento firme no acordo de pessoas racionais que querem instituir para si mesmas o grau máximo de liberdade igual. Para terem confiança na posse e no exercício dessas liberdades, os cidadãos de uma sociedade bem-ordenada normalmente desejarão que se preserve o império da lei" ${ }^{33}$.

Uma discussão interessante, e, diga-se de passagem, relevante para a presente temática, é indicada por Rawls numa nota, diz respeito à questão da liberdade e do direito. Rawls traz essa discussão à tona quando afirma que se pode ventilar se essa visão, que estabelece centrada na liberdade, vale para todos os direitos, como aquele que menciona ao tratar do exemplo dado por Hart, qual seja, o direito de se apropriar de alguma coisa que não foi reclamado por ninguém. No contexto dessa discussão, Rawls não faz prolongamentos, mas toma a posição de que os direitos especificados pela liberdade sejam suficientemente verdadeiros para o que propõe. Ademais, afirma o filósofo,

Embora alguns dos direitos básicos sejam analogamente direitos de competição, como poderíamos denominá-los -por exemplo, o direito de participar dos assuntos públicos e influenciar as decisões políticas-, ao mesmo tempo todos têm um dever de comportar-se de determinada

\footnotetext{
${ }^{61}$ Rawls, J., Teoria, p. 262.

${ }^{62}$ Talvez seja interessante pontuar, conforme salienta Solum, que se deveria adicionar à formulação de Rawls a ideia de que o governo, nos termos da lei, assim como a de que as ações do governo, ou as de seus funcionários, devem estar submetidas às regras gerais e públicas. Disso se segue que, por um lado, os funcionários governamentais não devem estar acima da lei, e por outro lado, que a legalidade da ação por parte do governo, deve estar sujeita a avaliaçôes por tribunais independentes. Cf. Solum, Laurence, Legal Theory Lexicon, s.v. The Rule of Law [disponível em, http, //www.uslaw.com/library/Academic/Legal_Theory_Lexicon_Rule_Law. php?item $=919063$, acessado em 20 de outobro de 2014]. É conveniente lembrar que Rawls entende que o princípio da equidade estabelece vínculos voluntários, bem como obriga indivíduos que ocupam cargos públicos.
}

${ }^{63}$ Rawls, J., Teoria, p. 262. 
maneira. Esse é um dever de conduta política equitativa, por assim dizer, e transgredi-lo constitui uma espécie de interferência. Como vimos, a constituição visa a estabelecer uma estrutura na qual direitos políticos que são exercidos equitativamente, e que têm seu valor equitativo garantido, tendem a conduzir a uma legislação justa e efetiva: "[...] Em outras palavras, podemos redescrever o direito como o direito de tentar fazer alguma coisa em circunstâncias específicas, circunstâncias essas que permitem a competição equitativa de outrem. A iniquidade torna-se uma forma característica de interferência”. ${ }^{64}$

É notória a distinção que Rawls faz no que respeita aos direitos básicos. Conforme Rawls, apesar de haver direitos de competição, entre os direitos básicos, como o direito de participar de atividades públicas e influenciar as decisões políticas tomadas, no esquema de cooperação social, todos têm um dever de conduzir-se de determinada maneira. Desse modo, o que está em questão é que para cada direito, visto do prisma individual, num esquema cooperativo, há um dever que se coloca no sentido social. Assim, o binômio direito-dever coloca-se no mesmo nível, embora o dever, por assegurar integridade ao esquema da cooperação, tenha mais proeminência. No caso em questão, a violação desse dever configura uma intromissão na liberdade alheia, portanto, no direito de outrem tendo em vista que feri um dever. $\mathrm{O}$ cumprimento dos deveres, pode-se arguir, assegura na cooperatividade os direitos, tendo em vista não o mérito moral, mas as expectativas legítimas.

Ainda, vinculado aos direitos de competição, entre os direitos básicos, Rawls enfatiza que o direito ("right") pode, então, ser descrito como direito ("right") de se tentar fazer alguma coisa em circunstâncias especiais, as que permitem a rivalidade de outros, de forma equitativa, justa ${ }^{65}$. A intromissão, o desrespeito e a intervenção à liberdade, nesse caso, seria um processo não-equitativo por não assegurar igualmente as condições de uma justa competição.

A conexão entre o estado de direito e a liberdade, segundo Rawls, pode

${ }^{64}$ Ibíd., p. 296, n. 23

${ }^{65}$ No original, em inglês, Rawls assim escreve, "Put another way, the right can be redescribed as the right to try to do something under specified circumstances, these circumstances allowing for the fair rivalry of others". Assim, ao afirmar que o direito é o direito de se fazer alguma coisa em circunstâncias especiais, Rawls está, na verdade, falando que, de acordo com a liberdade individual, algum indivíduo pode, ou não, fazer algo que lhe aprouver, isto é, tem o direito de fazer alguma coisa, numa circunstância especial. É notório, no que concerne aos direitos de competição, eles devem ser equitativos, no sentido de permitir uma rivalidade equitativa sob pena de, caso contrário, comprometer a equidade da cooperação social. RAWLS, J., Teoria, pp. 239. 
ser avaliada, ainda, por um viés diferente, que o aproxima de Hobbes ${ }^{66}$. Numa sociedade bem ordenada, os poderes coercitivos do governo são necessários para a estabilização da cooperação social haja vista que, embora os indivíduos saibam que partilham um senso comum de justiça e que cada um quer aderir às ordenações e instituições existentes, eles nem sempre podem ter plena confiança em seus pares. Isso porque podem suspeitar que alguns não estejam cumprindo com sua parte no esquema geral de cooperação social e, desse modo, sentirem-se tentados a não fazer a parte que lhes caiba. Nesse sentido "A generalização dessas disposições pode vir a provocar o colapso do sistema. A desconfiança de que os outros não estejam honrando seus deveres e obrigações aumenta com o fato de que, na ausência de uma interpretação autorizada e do cumprimento das normas, é bem fácil encontrar desculpas para infringi-las. Assim, mesmo em condições razoavelmente ideais, é difícil imaginar, por exemplo, um sistema voluntário de imposto sobre a renda que funcione bem. Esse tipo de arranjo é instável"67.

Para que essa instabilidade não ocorra e nem se generalize, Rawls enfatiza que o "papel de uma interpretação pública das leis legítima, apoiada em sanções coletivas, é precisamente o de superar essa instabilidade" ${ }^{68}$, o que, de fato, só efetivamente ocorre por meio de um sistema público de regras em que o governo afasta os motivos para se pensar que os outros não estão observando as regras. Em outras palavras, cabe ao ordenamento jurídico o papel dessa interpretação pública legítima das leis. Rawls conclui, então, que "Só por esse motivo, presume-se que um poder soberano coercitivo será sempre necessário, mesmo quando em uma sociedade bem-ordenada as sanções não sejam severas e talvez nunca precisem ser impostas. A existência de um sistema penal eficaz serve para garantir a segurança recíproca dos homens" ${ }^{69}$.

É pela via de um poder soberano coercitivo que, mesmo dentro de uma sociedade bem ordenada, em primeiro lugar, argumenta-se sobre a existência de um ordenamento jurídico, formado por um complexo de regras e normas públicas, endereçado a pessoas racionais, vinculado à proteção e garantia da liberdade, tendo em vista o estabelecimento de expectativas legítimas e, em segundo lugar, essa existência tem sua justificação. Esse ponto relaciona-se com a obediência ao direito, pois pela via da coerção, e tendo-se presente o que se protege, reforça-se nos indivíduos o desejo de cumprir com os encargos devidos.

\footnotetext{
${ }^{66}$ Rawls, J., Teoria, p. 297-8.

${ }^{67}$ Ibíd., p. 297.

${ }^{68}$ Ibíd., p. 263.

${ }^{69}$ Ibíd., p. 297-8.
} 
Quando finalizava a explanação acerca do estado de direito, Rawls salientou que, quando montam um sistema de sanções, as partes na convenção constituinte devem ponderar suas desvantagens, que são de duas espécies, segundo afirma o filósofo: $i$ ) a necessidade de cobrir os custos da manutenção do organismo (como exemplo, por meio de impostos); e ii) o perigo para a liberdade do cidadão representativo, medido pela probabilidade de que essas sanções venham a interferir erroneamente em sua liberdade.

Para Rawls, a criação de um ordenamento coercitivo é racional somente se essas desvantagens forem menores do que a perda da liberdade causada pelas instabilidades. Com isso, Rawls quer dizer que o aparato jurídico é um elemento que atua na estabilização social. Assim sendo, e uma vez que na convenção constituinte as partes escolheriam um aparato jurídico para integrar sua sociedade como uma instituição, a melhor ordenação para um sistema jurídico é aquela que minimiza as duas espécies de riscos acima descritas, isto é, o melhor sistema jurídico é aquele que, por um lado, não onera demasiadamente a sociedade com os custos para sua manutenção e, por outro, quando sua existência é de tal modo concatenada que dirima os perigos para a liberdade, através de sançōes. Ademais, em condiçōes iguais, está claro que os perigos para a liberdade são menores quando a lei é administrada imparcial e regularmente conforme a legalidade.

Os cidadãos de uma sociedade bem ordenada poderiam portar-se de um modo tal que não requisitasse a existência de um sistema jurídico, ou algo se assemelhasse a ele, em termos institucionais. Contudo, há por parte de Rawls, o entendimento de que se um mecanismo coercitivo é necessário, é obviamente essencial definir com precisão a modalidade de suas operações, pois conhecendo aquilo que penaliza, aquilo que proíbe e sabendo que está em seu alcance praticá-lo ou não praticá-lo, os cidadãos podem fazer seus planos de acordo com esta situação. É esse o sentido da afirmação de que um indivíduo que "obedece às leis tornadas públicas não tem nunca por que temer uma violação de sua liberdade" ${ }^{70}$ Evita-se, por meio de tais exigências, uma conotação tirânica materializada no ordenamento jurídico, que seria opressora da liberdade, em vez de deter-se e centrar-se na proteção das liberdades individuais, o ponto de toque com a liberdade por parte do ordenamento jurídico justo, isto é, aquele que é resultado da aplicação da justiça formal, caracterizado pelo estado de direito.

${ }^{70}$ Ibíd., p. 298. 


\section{CONSIDERAÇŌES FINAIS}

Do que se expôs, algumas conclusões podem ser aferidas. O ordenamento jurídico, como conceitua Rawls, é uma ordem coercitiva de normas públicas, do qual a finalidade, em primeiro lugar, é regular a conduta de pessoas racionais, ao mesmo tempo em que fomenta a estrutura da cooperação social, e cuja função o vincula à proteção das liberdades básicas individuais, estabelecendo, pois, uma base para expectativas legítimas numa sociedade bem-ordenada. Como uma instituição regulada pelos princípios de justiça, Rawls promove, desse modo, o encontro da justiça substantiva, definida pelos princípios da justiça, que assumem o papel da justiça, com a justiça formal, que encerra o princípio da legalidade. Portanto, quando aplicada ao sistema jurídico, a concepção formal de justiça e a administração regular e imparcial das normas comuns transforma-se no direito, por meio do estado de direito, que, caracteristicamente, por sua extensão, tem o poder de regular outras instituiçóes.

Sobre o direito, então, pode-se chegar a conclusão de que $i$ ) é possível caracterizar a instituição jurídica, uma vez que o filósofo estadunidense esboça uma teoria mais ampla das instituições como sistemas públicos de regras governadas por princípios mais gerais, os princípios de justiça. Como se defendeu]; ii) se a noção legalidade e de ordem jurídica é ampla, no sentido de que qualquer perspectiva substantiva de sistema jurídica que se configure como tal naturalmente apoiará, é também verdade que, de acordo com a afirmação anterior, a sua dinâmica instituicional implica que seja orientada por regras mais gerais, notadamente, os princípios de justiça, que são morais e reforçam os valores políticos.

Com efeito, iii) é coerente dizer que a concepção mais adequada ao entendimento do direito na teoria da justiça será sensível à recuperação das relações entre direito e moral, o que significa dizer que justiça como equidade não comporta uma concepçao positivista do direito. Ainda assim, iv) o direito é pensado com o propósito de proteger e assegurar as liberdades básicas, portanto, visto com um fim instrumental, vale dizer, promover a criação de expectativas legítimas para os indivíduos, bem como estabelecer as bases da cooperação social, ideia esta calcada na noção de reciprocidade.

$\mathrm{O}$ que distingue um sistema jurídico de outros conjuntos de normas públicas endereçadas a pessoas racionais, como apresentado, é a sua extensão, a sua abrangência e os seus poderes regulares em relação às associações da sociedade. O sistema jurídico tem institucionalmente o monopólio do direito legal de exercer as formas mais extremas da coação, circunscrita a um determinado território. Ademais, a ordem jurídica caracteriza-se pela extensa gama de atividades que regula e pela natureza fundamental dos 
interesses que se destina a assegurar. Noutros termos, ela tem o poder de regular as demais instituições sociais, tendo em vista a extensão de atividades que regula conjuminada aos interesses por ela assegurados. A lei, como uma de suas regras, é concebida, pois, como uma diretriz endereçada a pessoas racionais, já que estabelece e precisa a liberdade para agir. Institucionalmente, suas regras devem satisfazer os princípios de justiça - que assumiram o papel da justiça, como uma concepção de justiça, de tal forma que fornecem uma atribuição de direitos e deveres fundamentais, bem como determinam a divisão das vantagens advindas da cooperação social. Assim, $v$ ) a reflexão que Rawls faz do direito é caudatária da obra de dois importantes filósofos legais, a saber, Fuller e Hart. De Fuller, o entendimento de que há uma moralidade implícita ao direito nos termos da aplicação e administração imparcial e justa das regras públicas, conforme estabelecidas pelo estado de direito, que promove o encontro da justiça formal e substancial; de Hart, mais evidentemente, a caracterização do direito como sendo constituído por regras. Dessa forma, está claro que o modelo de Rawls é procedimental da regulação social consignando o princípio da igualdade e da reciprocidade, perspectiva sob a qual a ordem jurídica é uma parte considerável da teoria política de Rawls.

Com efeito, a concepção de justiça formal rawlsiana aplica-se diretamente às instituições, e não a pessoas -a não ser de modo indireto-, e especialmente nesse caso, às instituições jurídicas, com o objetivo de garantir e assegurar os direitos fundamentais individuais, estabelecidos, definidos e especificados pelos princípios de justiça, mediante o estado direito. $\mathrm{O}$ estado de direito é, então, o resultado da aplicação ao sistema jurídico da concepção formal da justiça, que como Rawls o descreve, está intimamente relacionado com a liberdade, visto que esta relação é evidenciada quando se considera a noção de sistema jurídico e de sua íntima conexão com os preceitos que definem a justiça formal. É permissível dizer que, mediante os preceitos do estado de direito, encontra-se a forma do direito em Rawls.

Tendo em vista assegurar-se a proteção dos direitos individuais no seio de uma sociedade democrática, Rawls postulou os seguintes preceitos como pertencendo ao estado de direito, a saber: $i$ ) o preceito dever implica poder; ii) o preceito casos semelhantes devem receber tratamentos semelhantes; iii) o preceito de que não há ofensa sem lei; e iv) os princípios da justiça natural. Estes preceitos são válidos como regras e princípios para o sistema jurídico, que, de certo modo, regula as demais instituiçōes da estrutura básica da sociedade. Assim, são diretrizes que garantem a legalidade da ordem jurídica. 


\section{BiBLIOGRAFíA}

Brooks, Thom (organizador), Rawls and Law (Farnham, Ashgate, 2012).

Dworkin, Ronald, A Justiça de Toga (São Paulo, Martins Fontes, 2010).

DwORKIN, Ronald, Justice in Robes (Harvard University Press, Cambridge, USA, 2006).

Dworkin, Ronald, Levando os direitos a sério (2a edição, São Paulo, Martins Fontes, 2007).

DwOrkin, Ronald, Uma questão de princípios (São Paulo, Martins Fontes, 2000).

Freeman, Samuel, Original Positio. em The Stanford Encyclopedia of Philosophy (Spring 2012) [disponivel em: http. //plato.stanford.edu/archives/spr2012/entries/ original-position/; acessado em 21 de outubro de 2014].

Freeman, Samuel, Rawls (New York, Taylor \& Francis, 2007).

Fuller, Lon, The Morality of Law (Revised Edition, Chicago, Chicago University Press, 1969).

Hart, H. L. A., O conceito de direito, (3a edição, Lisboa, Fundação Calouste Gulbenkian, 2001).

Hart, H. L. A., Rawls on Liberty and it's Priority, em Daniels, Norman (organizador), Reading Rawls. Critical Studies on Rawl' A Theory of Justice (Stanford, Stanford University Press, 1989).

KanT, Immanuel, Crítica da razão prática (Lisboa, Ediçōes 70, 1986).

Kant, Immanuel, Metafisica dos costumes (Lisboa, Fundação Calouste Gulbenkian, 2001).

Kelsen, Hans, Teoria pura do direito (3a edição, São Paulo, Martins Fontes, 1991).

LoIs, Cecília Caballero, O direito e o sistema dos direitos em John Rawls. Fundamento, validade e abrangência de uma teoria universal, em BuENO, Roberto (organizador), Racionalidade, justiça e direito. Ensaios em filosofia do direito.(Uberlândia, EDUFU, 2013).

Mandle, John, Rawls's A Theory of Justice. An Introduction (Cambridge University Press, New York, 2009).

Montesquieu, O espirito das leis (São Paulo, Abril Cultural, 1985).

Navarro, Emilio Martínez, Solidaridad liberal. La propuesta de John Rawls (Granada, Comares, 1999).

Perelman, Chaïm, Ética e direito (São Paulo, Martins Fontes, 1996).

Rawls S., John, O Liberalismo político (São Paulo, Ática, 2000).

RAWLS S., John, Uma teoria da justiça (São Paulo, Martins Fontes, 2009).

RAwls, John, $A$ Theory of Justice (Revised Edition, Cambridge, Harvard University Press, 2000).

RaWls, John, Collected Papers (Samuel Freeman editor, Cambridge, Mass, Harvard University Press, 1999).

RaWls, John, Justiça como equidade. Uma Reformulação (São Paulo, Martins Fontes, 2003).

Richardson, Henry - Weithman, Paul (organizadores), Philosophy of Rawls. A Collection of Essays (New York, Garland, 1999).

Rohling, Marcos - Volpato Dutra, Delamar José, O direito em "Uma teoria da justiça” de Rawls, em Dissertatio, 34 (Universidades Federal de Pelotas, 2011) 2.

Rohling, Marcos, Dworkin e a interpretação de Rawls como filósofo do direito, em Lex Humana, 4 (2012). 
Rohling, Marcos, Hart e Rawls. "Fair Play”. Obediência ao direito e obrigação política, em Lex Humana, 5 (2013) 2.

Rohling, Marcos, O conceito de lei. Lei legítima e desobediência civil na teoria da justiça como equidade de John Rawls, em Synesis, 6 (2014) 2.

Sarlo, Oscar, Supuestos de teoría jurídica en John Rawls, em Revista de Ciencias Sociales, 47 (Universidad de Valparaíso, 2002).

Solum, Lawrence, Legal Theory Lexicon, s.v. The Rule of Law [disponivel en: http, // lsolum.typepad.com/legaltheory/2014/11/legal-theory-lexicon-the-rule-of-law. html; acessado em 20/10/14.

Viola, Francesco, Rawls e il Diritto, em Biblioteca della libertà (gennaio-agosto, 2013), XLVIII.

Vorce, Paul, Rawls Explained (Chicago, Open Court, 2011).

Volpato Dutra, Delamar José, A legalidade como forma do estado de direito, em Kriterion, 109 (2004) 1.

Volpato Dutra, Delamar José, Justiça processual e substantiva na filosofia prática contemporânea, em BAVARESO, Agemir - HobUSS, João (organizadores), Filosofia, justiça e direito (Pelotas, EDUCAT, 2005).

Weber, Max, Economia e sociedade.. Fundamentos da sociologia compreensiva (Brasília, DF, Universidade de Brasília, 1999), II. 
